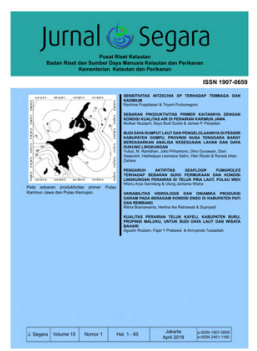

JURNAL SEGARA

http://ejournal-balitbang.kkp.go.id/index.php/segara

ISSN : 1907-0659

e-ISSN : 2461-1166

Nomor Akreditasi: 766/AU3/P2MI-LIPI/10/2016

\title{
SENSITIVITAS NITZSCHIA SP TERHADAP TEMBAGA DAN KADMIUM
}

\section{SENSITIVITY NITZSCHIA SP AGAINST COPPER AND KADMIUM}

\author{
Rachma Puspitasari \& Triyoni Purbonegoro \\ Pusat Penelitian Oseanografi, Lembaga IImu Pengetahuan Indonesia \\ Diterima : 23 Januari 2018; Diterima Setelah Perbaikan : 18 Januari 2019; Disetujui Terbit: 22 Januari 2019
}

\begin{abstract}
ABSTRAK
Penggunaan organisme uji yang sesuai dengan bahan yang diuji adalah faktor yang sangat penting dalam bioassay. Berbagai organisme uji tropis telah banyak digunakan di Indonesia seperti ikan, bulu babi, dan fitoplankton. Fitoplankton seperti Chaetoceros gracilis, Tetraselmis sp., Isochrysis sp., Pavlova sp., yang hidup di kolom air telah dimanfaatkan dengan baik untuk bioassay. Namun, fitoplankton bentik seperti Nitszchia sp. belum dikenal secara luas. Tulisan ini bertujuan untuk menguji potensi Nitzschia sp. sebagai biota uji sedimen. Parameter yang diteliti adalah kurva pertumbuhan dan sensitifitas terhadap kadmium dan tembaga. Hasil penelitian menunjukkan bahwa pertumbuhan Nitszchia sp. meningkat pesat pada hari keempat hingga hari keenam. Setelah hari keenam, pertumbuhannya cenderung menurun. Kepekaan terhadap toksikan diindikasikan dengan nilai IC50 (Inhibition Concentration) sebesar 0,078 mg/Luntuk tembaga dan 0,26 mg/L untuk kadmium. Kesimpulan dari penelitian ini adalah Nitszchia sp. dapat digunakan sebagai organisme uji untuk bioassay sedimen karena memenuhi persyaratan kepadatan minimum uji serta sensitif terhadap kadmium dan tembaga. Nilai LOEC dan NOEC untuk tembaga berturut-turut sebesar 0,056 dan $0,032 \mathrm{mg} / \mathrm{L}$ sedangkan untuk kadmium sebesar 0,18 dan $<0,18 \mathrm{mg} / \mathrm{L}$. Nitzschia sp. tiga kali lebih sensitif terhadap tembaga dibandingkan dengan kadmium.
\end{abstract}

Kata kunci: Nitzschia sp, bioassay, sensitivitas, kadmium, tembaga.

\section{ABSTRACT}

The use of representative test organism with the tested material is absolutely critical factor in a bioassay. Various tropical test organism have been widely used in Indonesia such as fish, sea urchins and phytoplankton. Phytoplankton such as Chaetoceros gracilis, Tetraselmis sp., Isochrysis sp., Pavlova sp., living in the water column had been well documented as test organism in bioassay project. However, benthic diatom such as Nitszchia sp. is not widely known. This paper aims to examine the potential of Nitzschia sp. as sediment bioassay test organism. Parameters studied were growth curve and sensitivity to cadmium and copper. Results show that the growth of Nitszchia sp. increased rapidly on the fourth day until the sixth day. After the sixth day, the growth hasb tend to decrease. Sensitivity to toxicants was indicated by IC50 (Inhibition Concentration) value of $0.078 \mathrm{mg} / \mathrm{L}$ for copper and $0.26 \mathrm{mg} / \mathrm{L}$ for cadmium. In this study, is concluses that Nitszchia sp. can be used as test organims for sediment bioassays because they meet the minimum density requirements as well as and sensitive to cadmium and copper. The values of LOEC and NOEC for copper were 0.056 and $0.032 \mathrm{mg} / \mathrm{L}$ respectively, while for cadmium were 0.18 and $<0.18$ $\mathrm{mg} / \mathrm{L}$. Nitzschia sp. three times more sensitive to copper than cadmium.

Keywords: Nitszchia sp., bioassay, sensitivity, cadmium, copper.

Corresponding author:

Jl. Pasir Putih I Ancol Timur, Jakarta Utara 14430. Email: poespitsari@gmail.com 


\section{PENDAHULUAN}

Perkembangan bioassay sebagai salah satu alat untuk monitoring kualitas lingkungan telah banyak dikembangkan di Indonesia. Bioassay memiliki beberapa keunggulan antara lain menyajikan efek biologis dari material tertentu seperti logam pada organisme akuatik. Ada beberapa metode bioassay yang sudah dikenal luas antara lain water only toxicant, whole effluent toxicant dan sediment bioassay (whole sediment toxicity dan elutriate sediment toxicity) (Burton \& Landrum, 2003).

Monitoring kualitas suatu perairan sangat ditentukan oleh kondisi sedimennya. Sedimen merupakan indikator kontaminasi yang baik karena berperan sebagai penyimpan berbagai kontaminan. Pengukuran kontaminan dalam sedimen lebih akurat dari bentuk terlarut dalam air karena konsentrasinya lebih stabil (Arifin et al., 2012). Sedimen merupakan habitat bagi organisme bentik dan epibentik serta banyak organisme yang dapat terpapar kontaminan melalui interaksi langsung atau tidak langsung dengan sedimen (CCME, 1995).

Salah satu faktor penting dalam bioassay adalah penggunaan biota uji. Variasi biota uji yang banyak dikenal adalah fitoplankton, ikan, bivalvia, dan ekinoderma. Mikroalga merupakan kelompok tumbuhan berukuran renik yang termasuk dalam kelas alga, diameternya antara 3-30 $\mu \mathrm{m}$, baik sel tunggal maupun koloni yang hidup di seluruh wilayah perairan tawar maupun laut, yang lazim disebut fitoplankton (Romimohtarto, 2004). Fitoplankton adalah organisme uji yang sering digunakan karena sensitif, cepat, murah dan memiliki relevansi ekologis (Arensberg et al., 1995). Pemilihan biota uji sangat berkaitan erat dengan material yang diteliti dan sifat hidup dari organisme tersebut. Fitoplankton yang hidup di kolom air seperti C. gracilis, Isochrysis sp, Pavlova sp. dan Tetraselmis sp. sudah banyak dikenal sebagai jenis organisme uji, namun tidak demikian halnya untuk fitoplankton bentik yang masih terbatas penggunaanya. Permasalahan yang ada di Indonesia adalah terbatasnya jenis organisme tropis untuk biota uji sedimen (Roman et al., 2007). Hogan et al. (2005) melaporkan bahwa Nitszhia closterium telah digunakan sebagai biota uji dalam penentuan Toxicity Identification Evaluation (TIE). Nitszschia sp. sebagai anggota dari Kelas Baccilariophyceae diketahui dominan di perairan Indonesia setelah Chaetoceros sp. seperti dijumpai di pesisir Tangerang (Wulandari et al., 2004) dan Belitung (Widianingsih et al., 2007). Oleh karena itu diharapkan jenis Nitszchia sp. di Indonesia pun mampu digunakan sebagai biota uji.

Sebelum menetapkan suatu organisme cocok sebagai biota uji, salah satu persyaratan yang harus dipenuhi adalah sensitif terhadap kontaminan tertentu, misalnya logam berat. Sensitivitas suatu organisme dapat diketahui berdasarkan nilai $I_{\mathrm{C}_{50}}$. Sensitivitas tinggi ditunjukkan dengan nilai $I_{50}$ yang rendah terhadap suatu material yang sama, misalnya logam tembaga dan kadmium. Logam berat dapat dibagi menjadi dua kelompok, logam berat esensial dan nonesensial. Logam berat nonesensial meliputi $\mathrm{Pb}, \mathrm{Cd}$, $\mathrm{Hg}, \mathrm{Cr}$, dan Ag. Logam berat nonesensial sangat beracun dan tanpa nilai gizi. Logam berat esensial seperti $\mathrm{Fe}, \mathrm{Mn}, \mathrm{Cu}, \mathrm{Mo}, \mathrm{Zn}$ dan Mg. Logam berat esensial penting sebagai mikronutrien pada sejumlah organisme tetapi beracun pada tingkat tinggi (Solisio et al., 2008). Konsentrasi logam berat tembaga di perairan meningkat sejalan dengan berkembangnya industrialisasi, pestisida, cat antifouling, fungisida, dan limbah buangan tambang (Zafer et al., 2007) sehingga isu tembaga di perairan dan efeknya pada organisme tetap menarik untuk diteliti.

Berdasarkan permasalahan tersebut, tulisan ini bertujuan mengulas tentang potensi fitoplankton bentik, Nitzschia sp. sebagai organisme uji yang sesuai untuk bioassay sedimen melalui pengukuran pertumbuhan dan sensitivitas logam tembaga dan kadmium. Hipotesis dalam penelitian ini adalah Nitszchia sp. sensitif terhadap logam kadmium dan tembaga sehingga dapat digunakan sebagai biota uji bioassay.

\section{METODE PENELITIAN}

\section{Kultur Nitzschia sp.}

Kultur murni Nitzschia sp. asal Karimun Jawa diperoleh dari laboratorium Marikultur-Puslit Oseanografi LIPI, yang dipelihara dalam air laut saring steril dan media Walne dengan EDTA (Walne, 1970) pada ruangan bersuhu $27 \pm 1{ }^{\circ} \mathrm{C}$, dan diberi penyinaran 12:12 jam dan aerasi secara terus-menerus. Untuk mengetahui laju pertumbuhan, satu ml kultur Nitzschia sp. diambil setiap hari selama 10 hari dan dihitung densitasnya menggunakan haemocytometer. Hasil perhitungan diplotkan pada grafik dengan umur kultur (hari) sebagai sumbu $x$ dan laju pertumbuhan $(\mathrm{sel} / \mathrm{mL})$ sebagai sumbu y.

\section{Bioassay Cd dan $\mathrm{Cu}$}

Metode yang digunakan adalah metode uji toksisitas statis tanpa penambahan toksikan selama pengujian menurut standar ASTM (2006). Penelitian dilakukan menggunakan lima perlakuan dan satu kontrol dengan tiga kali ulangan. Range Finding Test (RFT) atau uji pendahuluan dilakukan untuk mengetahui rentang konsentrasi logam berat yang akan digunakan pada uji definitif. Uji pendahuluan melibatkan satu kontrol dan tiga sampai lima konsentrasi uji dengan faktor pembeda 10 . Kemudian untuk penentuan konsentrasi dalam uji definitif mengikuti deret geometrik sehingga dapat diplotkan dalam skala logaritmik 
(ASTM, 2006; US EPA, 2002). Kisaran konsentrasi kadmium yang digunakan pada RFT adalah $0 ; 0,1 ; 1$; 10 dan $100 \mathrm{mg} / \mathrm{L}$ sedangkan untuk tembaga adalah 0 ; 1; 10; 100 dan $1000 \mu \mathrm{g} / \mathrm{l}$. Uji definitif dilakukan setelah memperoleh nilai $I_{50}$ hasil dari RFT. Kisaran konsentrasi dimana $\mathrm{IC}_{50}$ diperoleh dari RFT, dipergunakan sebagai dasar penentuan konsetrasi uji definitif. Kisaran konsentrasi kadmium yang digunakan saat uji definitif adalah $0 ; 0,18 ; 0,32 ; 0,56 ; 1,0$ dan 1,8 $\mathrm{mg} / \mathrm{l}$ sedangkan untuk tembaga adalah $0 ; 0,032 ; 0,056$; 0,$1 ; 0,18$ dan $0,32 \mathrm{mg} / \mathrm{l}$.

Logam yang digunakan adalah $\mathrm{CuSO}_{4} \cdot 5 \mathrm{H}_{2} \mathrm{O}$ dan $\mathrm{CdCl} 2.2 .5 \mathrm{H}_{2} \mathrm{O}$. Larutan uji dibuat dengan mengencerkan larutan stok dalam $1 \mathrm{~L}$ air laut saring steril yang telah ditambahkan media Walne nonEDTA dan kemudian dimasukkan ke dalam erlenmeyer sebanyak $100 \mathrm{ml}$ dan ditambahkan $1 \mathrm{ml}$ kultur Nitzschia sp. dengan kepadatan 1×104 sel/ml. Kultur Nitzschia sp. yang digunakan berumur 4 hari dan pengujian dilakukan dengan sistem batch culture artinya tidak ada penambahan nutrien ataupun toksikan selama pengujian berlangsung. Pengujian dilakukan dengan 3 kali ulangan pada masing-masing toksikan. Larutan uji yang telah dibuat kemudian diukur kualitas airnya menggunakan Water Quality Checker (Horiba U-50 Series). Parameter kualitas air yang diukur meliputi suhu, $\mathrm{pH}$, salinitas, dan oksigen terlarut.

Setelah 96 jam pemaparan, 0,9 ml larutan diambil dan ditambahkan $0,1 \mathrm{ml}$ larutan lugol sebagai pengawet. Kepadatan Nitzschia sp. (sel/ml) dihitung menggunakan haemocytometer. Uji dapat diterima jika kepadatan sel di dalam kontrol mencapai lebih dari $2 \mathrm{x}$ $105 \mathrm{sel} / \mathrm{ml}$ (ASTM, 2006).

\section{Pengukuran konsentrasi klorofil-a}

Pengukuran klorofil-a dilakukan secara fluorometrik mengikuti Cochlan \& Hendorn (2012). Sisa kultur fitoplankton disaring menggunakan filter
Whatman $0,45 \mu \mathrm{m}$ dan berdiameter $25 \mathrm{~mm}$. Setelah penyaringan, filter diekstraksi dengan menggunakan larutan aseton $90 \%$. Selanjutnya, disentrifugasi pada putaran $4.000 \mathrm{rpm}$ selama kurang lebih 30 menit untuk memisahkan filtrat dari cairan yang mengandung klorofil. Kemudian, cairan tersebut dibaca fluoresensinya dengan menggunakan fluorometer Turner Trilogy tipe AU-10.

\section{Analisis Data}

Respon kadmium dan tembaga terhadap kepadatan sel Nitszchia $s p$. dapat diketahui dengan memasukkan data jumlah sel ke dalam persamaan 1 atau 2. C merupakan kepadatan sel dalam kontrol dan T merupakan kepadatan sel dalam larutan perlakuan berbagai konsentrasi.

$$
\begin{aligned}
& I \%=\frac{C-T}{C} \times 100 \% \\
& S \%=\frac{T-C}{C} \times 100 \%
\end{aligned}
$$

Nilai $\mathrm{IC}_{50}-96$ jam Cu dan Cd terhadap Nitzschia sp. diperoleh dengan memasukkan data kepadatan sel ke dalam software ICPIN (Norberg-King, 1993). Nilai NOEC (No Observed Effective Consentration) dan LOEC (Lowest Observed Effective Consentratiom) diperoleh dengan software TOXSTAT (Gulley et al., 1990).

\section{HASIL DAN PEMBAHASAN}

Sebelum menggunakan Nitzschia sp sebagai biota uji, telah diteliti terlebih dahulu laju pertumbuhannya per satuan waktu. Hasil pengamatan setiap 24 jam Nitzschia sp. selama 10 hari disajikan pada Gambar 1. Nitszchia sp. mengalami lima

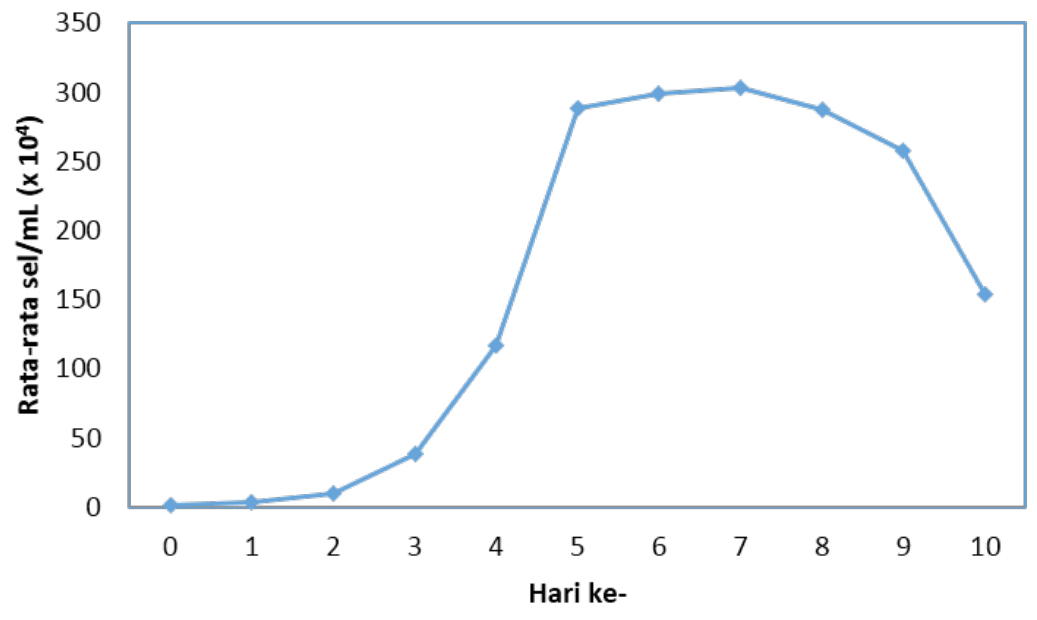

Gambar 1. Kurva pertumbuhan Nitszchia sp. selama 10 hari. 
fase berbeda yaitu fase lag, fase logaritmik atau eksponensial, fase berkurangnya pertumbuhan relatif, fase stasioner dan fase kematian (Richmond, 2004).

Fase adaptasi Nitzschia sp. terlihat dari peningkatan sel yang masih sangat sedikit menandakan pertumbuhan Nitzschia sp. yang belum maksimal pada hari pertama. Kultur Nitzschia sp. berada di fase logaritmik pada hari kedua hingga hari keenam periode kultur, Pada fase ini pertambahan sel terjadi sangat cepat,. Kepadatan tertinggi kultur Nitzschia sp. dicapai pada hari ketujuh dengan kepadatan $303 \times 10^{4} \mathrm{sel} / \mathrm{ml}$. Setelah melewati hari ketujuh periode kultur, kultur Nitzshia sp. mulai mengalami fase berkurangnya pertumbuhan relatif, fase stasioner dan mengalami kematian yang ditandai dengan menurunnya jumlah sel. American Standard for Testing Material mempersyaratkan agar kepadatan minimal kutur fitoplankton untuk pengujian adalah $1 \times 10^{4} \mathrm{sel} /$ $\mathrm{ml}$. Oleh karena itu, dari kurva pertumbuhan tersebut, umur kultur Nitzschia sp. yang dapat dipergunakan antara usia empat sampai enam hari kultur.

Pengujian definitif tembaga dan kadmium menunjukkan validitas dengan jumlah sel dalam kontrol berturut-turut adalah $4,78 \times 10^{5}$ dan $7,87 \times$ $105 \mathrm{sel} / \mathrm{ml}$ sesuai batas yang dipersyaratkan sebesar $2 \times 10^{5} \mathrm{sel} / \mathrm{ml}$ (ASTM, 2006). Kondisi ini menunjukkan bahwa nutrisi di dalam media selama 96 jam masih mendukung pertumbuhan sel di dalam kontrol. Tren penurunan jumlah sel Nitszchia sp. dijumpai seiring peningkatan konsentrasi kadmium dan tembaga. Begitupun kandungan klorofil-a Nitzschia sp. memperlihatkan tren yang serupa pada kedua logam (Gambar 2 dan 3). Tembaga merupakan logam esensial dan mikronutrien yang dibutuhkan untuk pertumbuhan dan perkembangan. Pada konsentrasi rendah diperlukan oleh mikroalga untuk transfer elektron fotosintesis, metabolisme sel, respirasi, dan kofaktor enzim yang membantu kerja enzim pada reaksi-reaksi tertentu dalam sel seperti fotosintesis (Andrade et al., 2004) tetapi beracun dalam konsentrasi yang lebih tinggi. Pada konsentrasi tembaga $0,18 \mathrm{mg} / \mathrm{L}$, penghambatan jumlah sel Nitzschia sp. mencapai 98,3\% dan penghambatan kandungan klorofil-a juga mencapai $97,4 \%$. Konsentrasi 0,078 mg/L tembaga menghambat pertumbuhan Nitszchia sp. sebesar $50 \%$ dan dinyatakan sebagai nilai $I_{50}$ Cu 96 jam. Nilai LOEC dan NOEC untuk tembaga berturut-turut sebesar 0,056 dan 0,032 mg/L. Pada konsentrasi 0,032 mg/L, tembaga tidak memberikan efek penurunan jumlah sel Nitzschia sp.

Tembaga dalam jumlah kecil dalam larutan akan diambil oleh sel Nitszshia sp. untuk aktivitas metabolisme, namun setelah melebihi batas kebutuhan (nilai NOEC sebesar 0,032 mg/L) maka tembaga mulai terserap dan menyebabkan penurunan jumlah sel. Perales Vela et al. (2007) mengatakan, kematian sel akibat keracunan diawali proses rusaknya kloroplas. Kerusakan kloroplas menyebabkan terhambatnya proses fotosintesis. Terganggunya aktivitas fotosintesis menyebabkankemampuanseluntukmemperbanyakdiri menjadi berkurang. Hal ini menyebabkan pertumbuhan dan pertambahan jumlah sel menjadi terhambat. Efek toksik dari logam berat Cu menurunkan pigmen klorofil pada Nitszchia sp. Konsentrasi logam berat $\mathrm{Cu}$ yang semakin tinggi mengubah struktur fikobiliprotein dan klorofil, dan perubahan ini mengakibatkan penurunan energi cahaya yang diserap, sehingga menghambat fotosintesis. Selain penurunan jumlah sel, pemaparan tembaga juga memengaruhi kandungan klorofil-a. Efek toksik dari logam berat Cu menurunkan pigmen klorofil pada Nitszchia sp. (Gambar 2).

Demikian pula kadmium, pada konsentrasi 1 $\mathrm{mg} / \mathrm{L}$ menghambat jumlah sel sebesar $92,3 \%$ dan menghambat kandungan klorofil-a sebesar $92.7 \%$ dibanding kontrol. Konsentrasi 0,26 mg/L cadmium menghambat pertumbuhan Nitszchia sp. sebesar

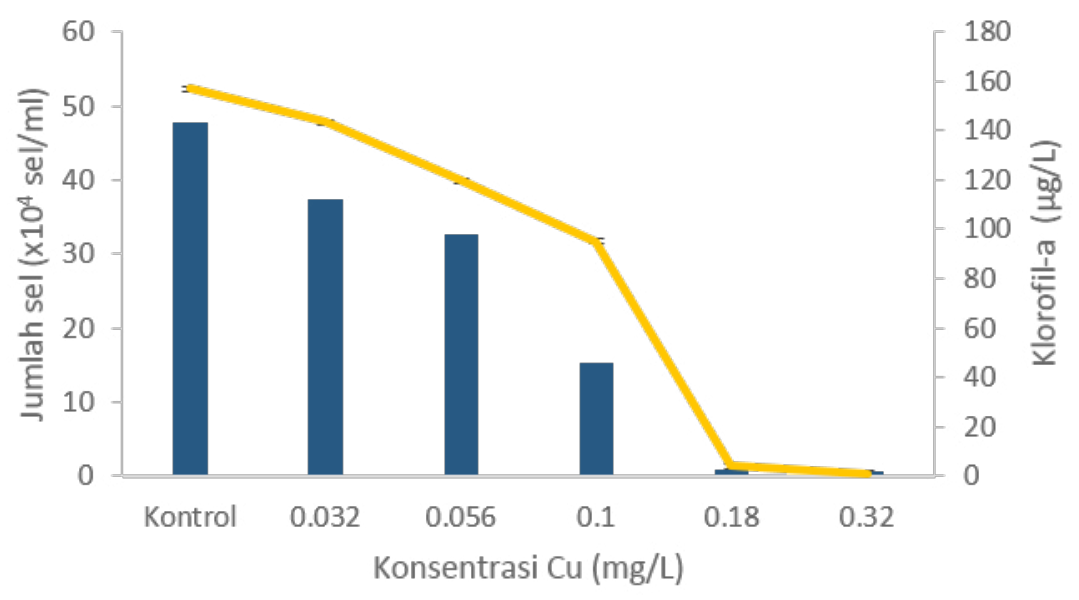

Gambar 2. Jumlah sel Nitzchia sp. dan klorofil-a setelah pemaparan dengan tembaga. 


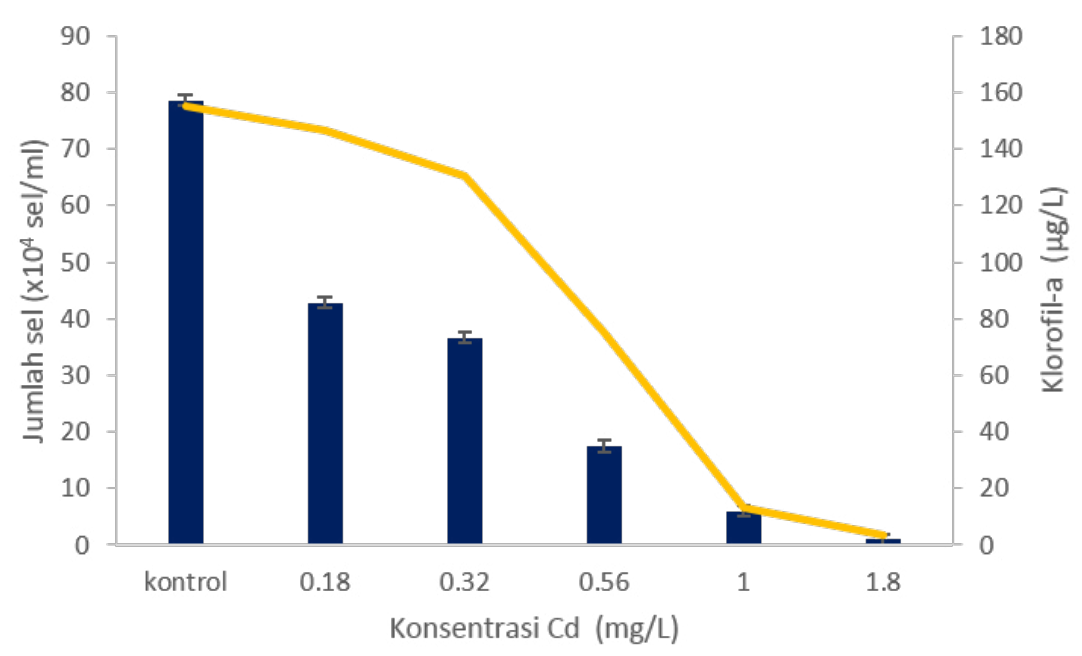

Gambar 3. Jumlah sel Nitzchia sp. dan klorofil-a setelah pemaparan dengan kadmium..

$50 \%$ dan dinyatakan sebagai nilai $\mathrm{IC}_{50} \mathrm{Cd} 96$ jam. Nilai LOEC dan NOEC untuk kadmium sebesar 0,18 dan $<0,18 \mathrm{mg} / \mathrm{L}$. Kadmium yang terserap oleh sel pada konsentrasi terendah yang diujikan yaitu $0,18 \mathrm{mg} / \mathrm{L}$ sudah menimbulkan efek penurunan jumlah sel karena kadmium merupakan logam berat nonesensial. Kadmium yang masuk ke sel akan terikat sebagai metalotionein di dalam tubuh fitoplankton. Metalotionein mengandung asam amino sistein, dimana $\mathrm{Cd}$ terikat dengan gugus sulfhidril (-SH) dalam enzim karboksil sisteinil, histidil, hidroksil dan fosfatil dari protein dan purin. Toksisitas $\mathrm{Cd}$ disebabkan oleh interaksi antara $\mathrm{Cd}$ dan protein tersebut, sehingga menimbulkan hambatan terhadap aktivitas kerja enzim (Lasut, 2002). Semakin tinggi konsentrasi kadmium maka akan semakin besar kerusakan yang terjadi di dalam sel sehingga pertumbuhan akan terhambat. Selain itu, kadmium juga dapat menggantikan logam Zn pada enzim Carbonic Anhidrase yang berfungsi dalam penyerapan unsur karbon. Kadmium juga dapat menyebabkan klorosis. Klorosis merupakan proses degradasi klorofil oleh pengaruh dari luar sel yang bersifat ekstrim. Klorosis yang disebabkan oleh logam berat kadmium dapat melalui dua jalur, yaitu penghambatan langsung terhadap enzim 5-asam aminolevulinat dehidratase yang berperan dalam sintesis klorofil, dan melalui penggantian logam besi $(\mathrm{Fe})$ dan magnesium $(\mathrm{Mg})$ yang terlibat dalam sintesis klorofil (Stobart et al., 1985). Selain itu, Falasco et al. (2009) juga memaparkan bahwa diatom dari jenis Nitzschia sp. dan Navicula sp. yang terkena stress dari lingkungan dapat mengalami bentuk-bentuk kerusakan teratologik. Bentuk kerusakan teratologik yang umum dijumpai adalah tipe 1, yaitu deformasi outline sel (hilangnya simetri untuk kedua sumbu; bentuk pentagonal atau trilobate,bergerigi, menoreh, berbentuk ginjal, bengkak, dan berbentuk bumerang.

Parameter kualitas air meliputi suhu, $\mathrm{pH}$, salinitas, dan oksigen terlarut diukur pada awal pengujian untuk memastikan uji berlangsung dalam kondisi normal dan sesuai dengan persyaratan metode standar (Tabel 1 dan 2).

\section{KESIMPULAN}

Berdasarkan persyaratan kepadatan awal sebagai biota uji, umur kultur Nitzschia sp. yang sesuai digunakan adalah empat sampai enam hari kultur. Nitszchia $s p$. juga memiliki sensitivitas yang baik terhadap tembaga dan kadmium ditunjukkan dengan nilai IC (In $_{50}$ (Ibition Concentration) yaitu 0,078 dan 0,26 $\mathrm{mg} / \mathrm{L}$. Nilai LOEC dan NOEC untuk tembaga berturutturut sebesar 0,056 dan $0,032 \mathrm{mg} / \mathrm{L}$ sedangkan untuk kadmium sebesar 0,18 dan $<0,18 \mathrm{mg} / \mathrm{L}$. Nitzschia sp. tiga kali lebih sensitif terhadap tembaga dibandingkan

Tabel 1.

Kualitas air larutan uji tembaga

\begin{tabular}{lllll}
\hline Kons. Nominal (ppb) & Suhu $\left({ }^{\circ} \mathbf{C}\right)$ & pH & Salinitas (ppt) & Oksigen terlarut (ppm) \\
\hline Kontrol & 25,36 & 7,51 & 32,2 & 5,1 \\
0,032 & 25,53 & 7,34 & 31,8 & 6,41 \\
0,056 & 25,5 & 7,75 & 32,1 & 4,37 \\
0,01 & 25,47 & 7,77 & 32,2 & 4,36 \\
0,18 & 25,4 & 7,77 & 32,2 & 4,14 \\
0,32 & 25,34 & 7,77 & 32,2 & 4,12 \\
\hline
\end{tabular}


Tabel 2.

Kualitas air larutan uji kadmium

\begin{tabular}{lllll}
\hline Kons. Nominal (ppm) & Suhu $\left({ }^{\circ} \mathbf{C}\right)$ & $\mathbf{p H}$ & Salinitas $(\mathbf{p p t})$ & Oksigen terlarut $(\mathbf{p p m})$ \\
\hline Kontrol & 25,36 & 7,51 & 32,2 & 5,1 \\
0,18 & 25,62 & 7,69 & 32,2 & 4,28 \\
0,32 & 25,71 & 7,76 & 32,3 & 4,35 \\
0,56 & 25,69 & 7,78 & 32,4 & 4,41 \\
1 & 25,6 & 7,78 & 32,3 & 4,08 \\
1,8 & 25,55 & 7,78 & 32,2 & 4,16 \\
\hline
\end{tabular}

dengan kadmium.

\section{PERSANTUNAN}

Penelitian ini terselenggara atas dana penelitian DIPA tahun 2018 Pusat Penelitian Oseanografi LIPI. Penulis juga mengucapkan terima kasih atas bantuan Sdr. Eston Matondang untuk kegiatan laboratorium.

\section{DAFTAR PUSTAKA}

Andrade, L.R., Farina M. \& Filho A.M. (2004). Effects of Copper on Enteromorpha flexuosa (Chlorophyta) in vitro. Ecotoxicol. Environ. Ecotoxicology and environmental safety. 58:117-125.

Arensberg, P., Hemmingsen V. H. \& Nyholm N. A miniscale algal toxicity test. (1995). Chemosphere 30:2103-2115.

Arifin, Z. Puspitasari, R. \& Miyazaki, N. (2012). Heavy Metals Contamination in Indonesian Coastal Marine Ecosystem: A historical perspective. Journal Coastal Marine Research 35(1) : 227-233.

ASTM. (2006). Standard Guide for Conducting Static 96-h Toxicity Testing with Marine Algae method E 12 18-19 in : Annual Book of Standards. Vol. 11.06 Biological Effects and Environmental Fate; Biotechnology; Water and Environmental Technology. ASTM International, West Conshohocken, PA. pp 58-78.

Burton, G.A. \& Landrum, P.F. (2003). Toxicity of sediments. In Encyclopedia of Sediment and Sedeimentary Rocks, G. V. Middleton, Church, M. J,. Corigilo, M., Hardie, L. A and Longstaffe (eds.). Kluwer Academic Publishers, Dordrecht, pp 748751.

Canadian Council of Ministers of the Environment. (1995). Protocol for the Derivation of Canadian Sediment Quality Guidelines for the Protection of Aquatic Life. 35 pp.

Cochlan W.P. \& Hendorn, J. (2012). Water Quality
Methods. Cochlan Phytoplankton Ecophysiology Laboratory. Romberg Tiburon Center for Environmental Studies San Fransisco State University Tiburon, CSA, USA. 317 pp.

Falasco. E., Bona, F., Ginepro, M., Hlubikova, D., Hoffmann, L., \& Ector, L. 2009. Morphological abnormalities of diatom silica walls in relation to heavy metal contamination and artificial growth conditions. Water SA .35(5): 595-606.

Gulley, D.D., Boelter A.M. \& Bergman H.L. Toxstat version 3.2. Fish Physiology and Toxicology Laboratory, Department of Zoology and Physiology, University of Wyoming, Laramie, WY.3 pp. 1990.

Hogan A. C., Stauber J. L., Pablo F, Adams M. S. \& .Lim R. P. 2005. The development of marine Toxicity Identification Evaluation (TIE) procedures using the unicellular alga Nitzschia closterium. Arch Environ Contam Toxicol. 48(4): 433-43. https://doi. org/10.1007/s00244-003-0137-y

Lasut, M.T. (2002). Metallotionein: Suatu Parameter Kunci Yang penting Dalam Penetapan Baku Mutu Air Laut (BMAL) Indonesia. Ekoton. 2(1): 61-68.

Norberg-King, T.J. A Linear Interpolation Method for Sub lethal Toxicity: The Inhibition Concentration (Icp) Approach (version 2.0). U.S. Environmental Protection Agency, Environmental Research Laboratory, Duluth, M.N. Tech. Report 03-93 of the National Effluent Toxicity Assessment Center. 30pp. 1993.

Perales-Vela, H.V., González-Moreno, S., MontesHorcasitas, C. \& Canizares-Villanueva R.O. (2007). Growth, Photosynthetic and Respiratory Responses to Sub-lethal Copper Concentrations in Scenedesmus incrassatulus Chlorophyceae). Chemosphere. 67:2274-2281.

Richmond, A. (2004). Biotechnology and Applied Phycology. Handbook of Microalgal Culture. 588 $\mathrm{pp}$ 
Roman Y. A., De Schamphelaere K.A.C, Nguyen L.T.H. \& Janssen C.R. (2007). Chronic Toxicity of Copper to Five Benthic Invertebrates in Laboratory-Formulated Sediment: Sensitivity Comparison and Preliminary Risk Assessment. Sci Total Environ 387:128-40.

Romimohtarto, K. \& Juwana, S. (2004). Meroplankton Laut Larva Hewan yang Menjadi Plankton. Djambatan. Jakarta.

Solisio C., Lodi, A. Soletto, D. \& Converti, A. (2008). Copper biosorption on Spirulina Platensis Biomass. Bioresource Tech. 99:5933-5937

Stobart, A.K., Griffiths W.T., Bukhari K.A. \& Sherwood R.P. 1985. The Effects of $\mathrm{Cd}^{2+}$ On the Biosynthesis of Chlorophyll in Leaves of Barley. Physiol. Plant. 63: 293-298.

US EPA. 2002. Methods for Measuring the Acute Toxicity of Effluents and Receiving Waters to Freshwater and Marine Organisms Fifth Edition. 43-44.

Walne P.R. (1970). Studies on the food value of nineteen genera of algae to juvenile bivalves of the genera Ostrea, Crassostrea, Mercenaria, and Mytilis. Fish. Invest. 26: 1-62.

Widianingsih, Hartati, R., Djamali, A. \& Sugestiningsih. 2007. Kelimpahan dan sebaran horizontal fitoplankton di perairan pantai timur Bangka Belitung. IImu Kelautan. 12(1): 6-11.

Zafer, A., Ekmekci, G., Vahdet, S. \& Ozmen, M. (2007). Heavy metal accumulation in water, sediments and fishes of Nallihan Bird Paradise. Turkey. J. Environ. Biol. 28: 545-549 
